\title{
Distribution in the Food Industry: Impact of the 2020 Truck Driver Shortage
}

\author{
Sarah Duggan \\ University of Central Arkansas \\ Mark McMurtrey \\ University of Central Arkansas
}

\begin{abstract}
Today's Food Industry is a world met with customers with a right-now mentality and increased expectations for special orders. Every day has become a battle of continuous improvement in order to meet customer satisfaction. In the past year alone, including pre-COVID-19, eleven of eighteen limited-service category restaurants have seen a decline in customer satisfaction. The greatest challenge is a lack of inventory. Nearly seventy percent of freight in America is distributed though the trucking industry, and there are not enough drivers to meet scheduling demand and deliver inventories. This paper examines the impact of the continuing truck driver shortage, and offers suggestions for ways that it may be alleviated. We also focus on how one very large, national fast-food chain has taken its own steps to address this situation as well as the impact of the coronavirus on all aspects of the supply chain. Benefits and limitations of these approaches are offered, along with exploring the notion that Ecommerce and last-mile Distribution Centers may be the answer for the future.
\end{abstract}

Keywords: food industry, restaurants, operations management, trucking, transportation, truck driver shortages, logistics, covid-19, supply chain management

\section{INTRODUCTION}

Today's Food Industry is a world met with customers with a right now mentality and increased expectations for special orders. Everyday has become a battle of continuous improvement in order to meet customer satisfaction. This year alone, including pre-COVID-19, eleven of eighteen limited-service category restaurants have seen a decline in customer satisfaction, including Chick-fil-A down by two points. The industry is down by $1.3 \%$ and full-service are seeing a higher decline in customer satisfaction at $2.5 \%$. (Kelso, 2020) Now more than ever, as more Americans eat out for most of their meals, there is an increased demand for speed as customers rush to get from point A to point B.

Restaurants are also seeing an increase in special orders from customers who desire to change standard menu items to better suit what they would prefer or get at home. With allergies and food intolerances being more prevalent today, food must be cooked and prepared to unique specifications that take more time. Order specialization negatively impacts speed of service and adds to difficulties and challenges in meeting customer needs. As restaurants work hard to evolve in meeting these needs, the greatest challenge is a lack of inventory. Receiving inventory on time from distribution centers has become an issue in the last several decades as the shortage of truck drivers continues to be a challenge. 


\section{Just in Time Inventory}

First introduced in the 1980's was a concept known as "zero inventories". This concept encompassed the idea of transporting inventory from outside venders to where the work is being done, to ensure that the finished product was done in a reasonable amount of time. This concept in manufacturing helps to decrease the cost of inspection, stocking, material handling, inventory tracking, and the risk of incurring damage or expiration that make inventory unable to be used. (Epps, 1995) This concept is now widely known in the food industry as "Just in Time Inventory".

Just in time inventory was developed by the Japanese in the 1980's. Before the 1980's, Japan was most known as an industrialized country, then it became known as one of the dominant economic powers in the world because of its cultural features and business practices. (Heiko, 1988) There are two reasons why Just In time inventory practices were mastered as they naturally became a way of life production and delivery systems for the Japanese. Japan is a heavily populated, dense, urban country which leaves them in a position to have little space to work with when it comes to storing materials. (Heiko, 1988) Because of this, they need to be able to store only what they need or have forecasted to need. In addition to storage capacity constraints, the Japanese are also met with food storage constraints. Most of the Japanese diet is seafood and served raw. Seafood is highly perishable, and therefore, in order to serve it safely, it must be carefully supplied so it can be served in the time frame it is needed. (Heiko, 1988) Japan's natural adjustment in production systems to meet inventory turnover needs due to space and perishable foods has allowed them to become a leading example for the world in just in time inventory benefits and effective practices.

Just in time inventory systems are centered on receiving goods needed for production as close to the time they are needed as possible. This helps to reduce potential waste and costs associated with spoilage or overstock, reduce costs associated with stealing, and overstock storage space issues. (Jacobs and Chase, 2020) Since just in time inventory systems plan for expected demand just as the items are needed for production, any lag time in arrivals of inventory distribution from Distribution Centers results in shortage of inventory needed for production. Similarly, the inability to serve orders in restaurants due to the shortage of inventory results in costs associated to lost sales during the time of shortage, and in the future as they lose credibility and trust with their customers due to inconsistency in ordering speed or ability to fulfil orders. As standards are continuously set higher for speed of service and specialized orders, one customer disappointment in unmet expectations can cause long term negative financial repercussions as these mistakes sometimes lead to loss of customer retention. It is imperative, therefore, that today's Food industry understand the truck driver shortage and how to respond to, eliminate, or minimize production issues caused by the shortage.

\section{Just in Time Inventory and Distribution}

In 1984, Professor Mayer, a Professor in Business Administration at Layola University, brought to light several concerns in relation to Just in time inventory and the effects and costs it could have on businesses. One concern was the potential additional costs that would be allocated to each case of product as more shipments were required more often with less inventory in each shipment, increasing the cost of delivery per case. The other concern highlighted is the location of each warehouse in reference to its assembly plant. The amount of the cost incurred by an increased number of shipments would be dependent on the location of the plant. A potential proposed solution would be building or relocating warehouses closer to where products are being assembled to aid in maintaining costs. (Mayer, 1984)

As Just in time inventory becomes more prevalent in the practices of businesses, business processes require inventory to arrive only when it is going to be needed or forecasted in order to be efficient. This results in a need to receive inventory shipments more frequently and in smaller batches that meet their production schedule. Distribution centers have steadily experienced more pressure from the demands of its customers as the need to provide more deliveries more often has increased. This requires more extensive delivery schedules for shipments and more drivers to make those deliveries. Companies need to know that they can rely on their suppliers to get them the inventory they need when they need it. It is crucial for companies to evaluate their suppliers to make sure that they can keep up with demand and that inventory can be received on schedule. Because of the extense evaluation of suppliers to ensure that they can be 
depended on, many companies who operate with a Just in time System have decreased the number of suppliers that they use. (Deakin, 1988)

\section{TRUCK DRIVER SHORTAGE}

The annual Top Industry Issues Report from the American Transportation Research Institute conducted a survey of carriers and drivers, and for the second year in a row, the truck driver shortage is a top concern ranking third on the 2018 list. (Jaillet, 2018) The truck driver shortage in America is not a new problem, but one which has become increasingly more concerning. Nearly seventy percent of freight in America is distributed though the trucking industry, and there are not enough drivers to meet scheduling demand and deliver inventories. This has impacted costs of produce and packaged goods. (Dawson, 2018)

The food industry is growing and moving more towards lean production and Just in time inventories, and there are not enough qualified drivers to meet the demand of the Industry. Paul Burton, the director of logistics and distribution at JTM Food Group says, "One of the first Pieces I see it affecting is lead time". (Dawson, 2018) Restaurants are moving more towards lean production and just in time inventories now more than ever. The negative effect on lead time because of a driver shortage is already causing inventories to be scarce or insufficient, and leading to complications in operations, increased cost as restaurants try to supply items from local stores until stock can arrive, and a loss in customer sales and satisfaction as some items may not be able to be offered for sale until inventory is replenished.

The trucking industry has dealt with a driver shortage since 2005. Until recently, the shortage was not concerning as it has always consistently leveled back out. There was a shortage in 2007-2009 that was attributed to the recession as driver employment decreased. In 2013, the shortage had leveled back out to around 2.9 million drivers, which is what the industry was seeing in 2003. In 2016, there was another jump in the supply in drivers. (Berman, 2019) In 2017, the American Trucking Associations predicted the highest level of driver shortage. The 2017-2018 shortage was attributed to the electronic logging device mandate that required more drivers to do the same amount of miles that drivers were doing before the logging device and there were not enough drivers to get the same amount of work done. (Gross, 2019)

It is estimated that by 2026 the shortage could increase to 174,000. (Dawson, 2018) The truck driving industry is not an industry that is easy for recruitment as it usually requires workers to be away from home for long periods of time and have high productivity demands to meet. (Gross, 2019) Even with consistent raises in pay to attract qualified drivers, driver retention has become more difficult as demands on scheduling increase.

\section{Proposed Solutions}

As just in time inventory became more popular in business practice in the 1980s after the business example of the Japanese, the trucking industry also began to see a shortage of drivers. ATA's chief economist Costello, points to driver pay as one of the ongoing challenges of the truck driver shortage. (Berman 2019) However, it was also shown that pay solved the shortage problems temporarily causing the inconsistency in the shortage since 2005. The industry has been raising truck driver wages since the 1980s in order to make the profession more appealing to the population, but the effects are always short lived as truckers struggle with time away from home, long hours on the road, and increased demands in meeting time constraints in distribution.

These time constraints were even made harder in 2017 when they required the time logging devices. When driver turnover began to increase to its highest levels during this time, wages were increased to help mitigate the shortage. According to the National Transportation Institute, wages increased on average by ten percent in 2018 while the industry was responding to the shortage. (Gross, 2019)

One potential solution that could make finding new drivers easier in the long run, is to increase the population in which the industry can recruit from. As of 2019, the industry population of drivers is made up of over ninety-seven percent men. This leaves a huge opportunity with less than seven percent being female.(Black, 2019) If the industry could find a way to appeal and reach out to the female population, they could dramatically increase their population of potential drivers. 
Another way to increase the population pool, is change the age requirements for drivers that can cross state lines. Right now, the minimum age for qualified drivers is 21. The American Trucking Association based out of Arlington, Virginia, is proposing that the age regulations be lowered to be the age of 18 . Lowering the age could be a crucial step for the industry as it would allow men and women to enter the industry directly out of high school. (Black, 2019) There are a minimum number of trades that high schoolers can begin work in such as construction or food service right out of high school without going to college or getting licenses in trades like plumbing, electrical, or welding that would take time and cost money.

If high school graduates over 18 were able to enter directly into the trucking industry, it would allow more career options for today's young adults, and would be another way to increase the population of potential drivers for recruiting during times of shortages. Not to mention that the population of qualified drivers is beginning to run out as the average age of drivers is now 49, (Dawson, 2018) and it would be future minded for the industry to increase the qualified population by lowering the age and potentially jumpstarting a new wave of drivers for the future.

Another unique solution to the shortage and issues causing the shortage is one in which only one restaurant has braved. That restaurant is Chick-fil-A. Chick-fil-A operates on just in time inventory and lean production. Chick-fil-A corporate saw the frustration of its restaurant owners and proposed a solution to the truck driver shortage and growing sales in the restaurants. In 2019, the corporate office opened its first Chick-fil-A Supply Center in Cartersville, GA. Instead of counting on its distribution centers for on time and fulfilled deliveries, Chick-fil-A stepped outside of the box and opened their own last-mile distribution center. Their focus on a successful distribution center is a focus on care as they serve up to 300 restaurants alleviating stress from the growing needs of the restaurants in just in time inventory. The center has been so successful that they just announced the opening of their second Chick-fil-A Supply Center in Mebane, North Carolina. (McGinty, 2020)

\section{Challenges to Proposed Solutions}

An increase in driver pay worked to lower the shortage, but not forever. The industry still struggles to find drivers that are willing to work the job at the pay that is available. Challenges will continue to effect the industry such as increased regulatory restrictions that make it harder for drivers to perform their job and meet demand, recessions that result in lack of need for drivers and layoffs, and economic growth at a rate that restricts the industry's ability to hire and train qualified drivers quickly enough to meet the increased demands (Gross, 2019) If an increase in driver pay is only a short term solution, constantly having to be revisited, the industry must take some steps to find a long term solution.

Increasing the population of qualified drivers by working to bring more women into the field and lower the age of the drivers to 18 , could be a potential effective adjustment going into the future as the average age of drivers continues to get older. However, even lowering the required age to 18 may impose costs of training and monitoring, along with the continually increasing wage rates that trucking companies may not be able to maintain financially. (Black, 2019) And lastly, even though the innovation of the Chick-fil-A Supply Centers offering last-mile distribution service to its owners has been successful, the capacity and finances may not be there for other restaurants to do the same.

\section{Distribution and Ecommerce}

Despite proposed solutions to the truck driver shortage we have seen come and go up until today, it is possible that as new leadership enters into the White House in 2021, new regulations on the truck driving industry may pose threats to more issues in the truck driving industry as more strenuous regulations are put on drivers. These regulations could increase productivity challenges making the job even harder for drivers to meet demands. (Gross, 2019) While trying to find a consistent, long-term solution to the truck driver shortage, restaurant owners and operators are still struggling to meet demand in restaurants as trucks are still consistently arriving late or not at all due to distribution centers inability to provide enough drivers to meet the demands of increased demands in scheduling in response to lead production with just in time inventory. 
In efforts to alleviate some of the challenges, the food industry began to see a shift towards increased ordering through online marketplaces as early as 2014. A 2014 report shows that nearly twenty-seven percent of restaurant operators are buying online at least once a month. Ordering online has not only allowed restaurant operators to cut costs by twelve to thirteen percent but has given operators the opportunity to get items that they need sooner. In the initial shift to online purchasing, restaurants were mainly only ordering nonfood inventory and dry goods inventory, but if ways to control food quality in online ordering are possible there was expected a shift to online marketplace inventory ordering to become more prevalent in the restaurant industry. (Smith, 2015)

As ecommerce continues its growth, it proposes new challenges to the long-haul truck carrying companies. The population of qualified drivers for hire has not changed much, however, what has changed is the increase in ecommerce. As ecommerce continues to grow, what larger trucking companies are seeing, is a shortage of available drivers as qualified drivers choose to accept jobs with local companies that are focused on last-mile delivery to its customers and shorter-haul runs between warehouses. (Cassidy, 2020) However, as the increase for just in time inventories in the foodservice industry and the shift to ecommerce has opened a door for distributors to find a way to source produce locally with farms. (Romeo, 2020) This shift will make the demands of frequent orders from restaurants due to just in time inventory systems and lean production easier to accomplish for distributors as they will be sourcing with last-mile delivery. Lastmile deliveries are made by smaller trucks that do not require the special licenses required for drivers on long-haul deliveries. (Romeo, 2020) The increase in last-mile delivery from this could have a positive impact on the future truck driver shortage as the need may potentially decrease in long-haul delivery as more distributions make a potential shift to last-mile.

\section{COVID-19: DISTRIBUTION AND TRUCK DRIVER SHORTAGE}

In 2020, business has seen unprecedented times. Businesses have been learning to adapt as COVID-19 has changed the game for how business can be running. Restaurants are still affected by the truck driver shortage. In April, as business slowed down with, he onset of COVID-19, the shortage was not an issue. (Cassidy, 2020) However, that was only short-lived as businesses began to reopen, and consumers began to leave the house again, restaurant owners not only began to experience normal setbacks in just in time inventory due to the challenges of late trucks due to a driver shortage, but they also had a new problem. That problem was increased to no trucks at all for extended periods of time, or the inability to receive some product as witnessed here in our local restaurants, specifically Chick-fil-A. Our local Chick-fil-A restaurants went from receiving five truck deliveries a week to only two due to the driver shortage and COVID-19 restrictions on warehouses making it impossible to operate on a just in time inventory system. (Demonbruen, Jacquelyn, Martin Brower, personal communication, March 2020)

The driver shortage seemed to escalate as ecommerce took off and drivers were disqualified due to positive testing with the US Commercial Drivers License and Drug and Alcohol Clearinghouse when it opened in January. Over 30,000 drivers were excluded from driving as they tested positive, and around 24,000 of those drivers have not returned to work which is the equivalent of almost eleven percent of the population of qualified drivers. (Cassidy, 2020) As Smith notated in his article, restaurants had already begun the shift to ecommerce in 2014 in response to needing to meet demand and get things when they needed them. The only challenge that they had at the time was a lack of grocery options to purchase online and were limited to dry goods and other inventories. (Smith, 2015)

Now, with the major shift to ecommerce due to COVID-19 restrictions and needing inventory to be sourced amidst COVID-19 restrictions on warehouses, there is beginning to become an online grocery marketplace. The shift has already been made to household ordering, which may open the door to availability of non-dry goods to restaurants and other retailers. For Example, online grocers doubled in March alone after the initial wave of COVID-19 to 40million from 20million in February. (Miller, 2020) 


\section{Setting the Stage for the Future}

The challenges brought from COVID-19 affected everyone at every stage of the distribution and consumer channels in the Supply Chain. As businesses learned how to adapt to operate under COVID-19 safety, they had to change the way they were doing things. This necessity for survival for businesses has potentially changed the way our businesses may operate going forward. What this innovation in light of the pandemic did was begin to tackle at a higher pace some challenges that the warehousing and distribution industry were already seeing before the pandemic. "According to Rich Thompson, international director, supply chain and logistics solutions at JLL, the pandemic has 'put a spotlight' on several major developments in supply chain management. The need for more warehouse automation and technology; a growing emphasis on e-commerce; a diversification of sources; and network redesign to accommodate all these" (Miller, 2020)

The growth of ecommerce has increased from $11 \%$ in 2019 to $15 \%$ already in 2020 with expected forecast of a growth to $30 \%$ over the next few years. (Miller, 2020) Companies are adapting to the pandemic with ecommerce solutions and the growth of ecommerce is starting to and will be changing the model of distribution for businesses into the future. These changes will assist in alleviating some of the challenges to lean production and just in time inventories that have been caused by the truck driver shortage. The shift to ecommerce will allow a change in labor needed due to technology and a potential elimination of distributers all together.

Warehouses that would normally use labor as the distribution centers would turn into fulfillment centers where robotics would sort orders and these fulfillment centers would be located closer to urban areas. These centers would be considered "last mile" distribution centers (Miller, 2020) These last mile distribution centers are the jobs that are in highest demand for todays truck drivers as they prefer to work locally, not having to be further away from home, and not having the same performance demands as the long haul trucking companies do. This potential future shift could help to minimize and develop a long-term solution to the truck driver shortages that have been seen since 2018 .

\section{CONCLUSION}

As restaurants strive to meet customer service demands of fast service and specialized orders, they have been challenged by distribution constraints caused by the truck driver shortage. Even though businesses and restaurants were already adjusting, COVID-19 forced the industry to quickly accommodate to the delivery schedule demands and unmet deadlines caused by the driver shortage. Up until this point, the truck driving industry mainly focused on an increase in driver pay to temporarily solve shortages, making the job more appealing to potential qualified drivers.

In 2020, advancements and innovation are being made in distribution that are setting the stage for a new future and providing long-term solutions to the shortage of truck drivers. The introduction of last-mile distribution centers due to the growth in ecommerce, is decreasing the need for qualified truck drivers because the smaller trucks used in last-mile distribution do not require certifications for drivers. In addition, Chick-fil-A has stepped completely out of the box and opened their own last-mile distribution centers to serve their own restaurants. The population of drivers find these last-mile driving jobs more appealing because the job allows them to stay closer to home and alleviate some of the demands of distribution scheduling caused by just in time inventory demands in the food industry. Ecommerce and last-mile Distribution Centers may be the answer for the future. 


\section{REFERENCES}

Berman, J. (2019). Bureau of Labor Statistics report downplays impact and severity of truck driver shortage. Supply Chain Management Review, 23(3), 62-65. Retrieved from https://searchebscohost-com.ucark.idm.oclc.org/login.aspx?direct=true \&db=bth\&AN=136545487\&site=bsilive

Black, T. (2019). U.S. Truck Driver Shortage Is on Course to Double in a Decade. Bloomberg.Com, N.PAG. Retrieved from https://web-a-ebscohostcom.ucark.idm.oclc.org/bsi/detail/detail?vid=4\&sid=0e1e8fb3-ea4d-4455-a100$19 \mathrm{ba} 901 \mathrm{bc} 2 \mathrm{~b} 2 \% 40 \mathrm{sdc}-\mathrm{v}-$ sessmgr01\&bdata $=$ JnNpdGU9YnNpLWxpdmU\%3d\#AN=137687466\&db=bth

Cassidy, W.B. (2020). Driver-Shortage: Barriers to new truck capacity rising: ATA's Costello. JoC Online, N.PAG. Retrieved from https://web-a-ebscohostcom.ucark.idm.oclc.org/bsi/detail/detail?vid=7\&sid=2414d359-5304-41af-b6c9f2a6804affb5\%40sdc-vsessmgr02\&bdata=JnNpdGU9YnNpLWxpdmU\%3d\#AN=146507197\&db=bth

Dawson, G. (2018). Truck driver shortage impacting deliveries: Expect delays and price hikes. $S N$ : Supermarket News, 26. Retrieved from https://eds-a-ebscohostcom.ucark.idm.oclc.org/eds/pdfviewer/pdfviewer?vid=2\&sid=10203e8d-0e5c-453c-9919$41 \mathrm{a} 5087 \mathrm{c} 21 \mathrm{dc} \% 40$ sessionmgr101

Deakin, E.B. (1988). Supplier Management in a Just-In-Time Inventory System. Journal of Accountancy, 166(6), 128-133. Retrieved from https://eds-a-ebscohostcom.ucark.idm.oclc.org/eds/pdfviewer/pdfviewer?vid=2\&sid=e8ffe21c-c3c3-4589-9759a541251760d0\%40sdc-v-sessmgr01

Epps, R.W. (1995, Fall 5). Just-in-time inventory management: Implementation of a successful program. Review of Business, 17(1), 003464549. Retrieved from https://eds-a-ebscohostcom.ucark.idm.oclc.org/eds/detail/detail?vid=4\&sid=be9cf659-cc74-448e-b756$15688898 \mathrm{ff02} \% 40$ sessionmgr 101\&bdata $=$ JnNpdGU9ZWRzLWxpdmUmc2NvcGU9c210ZQ\%3d $\% 3 \mathrm{~d} \# \mathrm{AN}=9512242195 \& \mathrm{db}=\mathrm{bth}$

Gross, L. (2019). From shortage to scarcity. Journal of Commerce (1542-3867), 20(23), 29. Retrieved from https://web-b-ebscohostcom.ucark.idm.oclc.org/bsi/pdfviewer/pdfviewer?vid=3\&sid=54d5b8a7-25be-497f-88979dec6d576fd7\%40pdc-v-sessmgr06

Heiko, L. (1989). Some Relationships between Japanese Culture and Just-in-Time. The Academy of Management Executive (1987-1989), 3(4), 319-321. Retrieved from https://eds-a-ebscohostcom.ucark.idm.oclc.org/eds/pdfviewer/pdfviewer?vid=2\&sid=247b51df-9af4-4927-a166a6dc45f4e908\%40sdc-v-sessmgr02

Jacobs, R.F., \& Chase, R.B. (2020). Operations and Supply Chain Management: The Core (Fifth Edition). Jaillet, J. (2018). Driver Shortage Tops Survey of Industry Issues. Overdrive, 58(12), 20. Retrieved from https://web-a-ebscohost-com.ucark.idm.oclc.org/bsi/pdfviewer/pdfviewer?vid=4\&sid=5812eba1f768-4ed4-94fe-a24cb22c6a16\%40sdc-v-sessmgr01

Kelso, A. (2020, June 30). Editors Pick: Chick-fil-A Named America's Favorite Restaurant Chain For the Sixth Year. Forbes. Chick-Fil-A Named America's Favorite Restaurant Chain For The Sixth Straight Year.

Mayer, R.R. (1984). A critical look at Kanban, Japan's just-in-time inventory system. Management Review, 73(12), 48. Retrieved from https://eds-a-ebscohostcom.ucark.idm.oclc.org/eds/pdfviewer/pdfviewer?vid=3\&sid=cc0bb5a2-71 c6-4d93-b130cc51bd1d67bc\%40sessionmgr4007

Miller, M. (2020). Covid-19's impact on warehousing might last longer than the pandemic: The Covid-19 impact on warehousing and distribution could well outlast the pandemic itself, as new sourcing 
options, altered supply chains and a new wave of warehouses and distribution centers closer to consumers emerge. American Journal of Transportation, 708, 8-12.

McGinty, J. (2020, September 4). Innovation meets demand: Introducing Chick-fil-A Supply. The Chicken Wire. Innovation meets demand: Introducing Chick-fil-A Supply | Chick-fil-A.

Smith, S. (2015). Distribution Goes Digital. Restaurant Business, 114(8), 25. Retrieved from https://weba-ebscohost-com.ucark.idm.oclc.org/bsi/pdfviewer/pdfviewer?vid=4\&sid=ee7eefd6-0444-4a5995e7-99b4d0b86715\%40sessionmgr4006

Romeo, P. (2020, January 16). Operations: The Future of The Supply Chain. Restaurant Business. The Future of the Supply Chain. 